\title{
STUDY OF BIOLOGICAL SABATIER REACTION WITH FLUID DYNAMICS SIMULATIONS
}

\author{
Grazia Leonzio ${ }^{1}$ \\ ${ }^{I}$ PhD Student, Department of Industrial and Information Engineering and Economics, University of L'Aquila, Via \\ Giovanni Gronchi 18, 67100 L'Aquila, Italy
}

\begin{abstract}
An alternative to catalytic Sabatier reaction is the biological Sabatier reaction that may be a suitable option for the future energy storage. In this paper a computational fluid dynamics analysis is carried out to study the mixing inside the anaerobic digester, to evaluate the gas to liquid mass transfer and the efficiency of this biological reaction. A detailed modeling about hydrodynamics and mixing is developed. The standard $k-\varepsilon$ mixture turbulence model and the Eulerian-Eulerian approach are used to simulate the flow inside the anaerobic digestion. External sludge re-circulating pumps are present as system mixing. Results of simulations show that with higher liquid velocity there are the higher mass to transfer from gas to liquid and turbulent dissipation rate. A sensitivity analysis is carried out to evaluate the influence of reactor pressure on methane evolution rate and methane content in the off gas: the effect is positive for the two responses. The future construction of the anaerobic digester will provide the obtained results.
\end{abstract}

Keywords: Anaerobic Digester, Mixing System, Computational Fluid Dynamics, Biological Sabatier Reaction, Mass Transfer From Gas To Liquid, Methane Evolution Rate

\section{INTRODUCTION}

Today different renewable and sustainable energy alternatives are used to replace non-renewable fuels due to the limited stock of non-renewable sources (oil, natural gas and coal), the deleterious effect that their consumption has on the environment [1].

In this context, carbon dioxide is an important element because it is a waste producing fuels as methanol or methane.

In general carbon dioxide has different origin: is obtained from cleaning of biogas and syngas [2, 3], thermal plants [4], from air [5] or other industrial processes.

The increasing carbon dioxide concentration in the atmosphere is the main cause for the increasing greenhouse effect with consequent climate change. So carbon capture and utilization technologies (CCU) are used to reduce the concentration of greenhouse gas from atmosphere [6].

Among of them carbon dioxide is used to produce valuable chemical products. A process to produce methane by converting carbon dioxide and hydrogen is known as Sabatier reaction (see Eq. 1).

$\mathrm{CO}_{2}+4 \mathrm{H}_{2} \leftrightarrow \mathrm{CH}_{4}+2 \mathrm{H}_{2} \mathrm{O}$

Concentrations of methane higher than $95 \%$ in the produced gases allow to obtain bio-methane and it is related to biomethane potential of the organic wastes.
In general hydrogen is produced bydifferent means as electrolysis of water, direct photolytic water splitting, thermal-catalytic water splitting, and biomass gasification [7].

Electrolysis of water can be obtained using hydro, solar or wind energy. Photochemical reaction is carried out using energy directly from the sun, while thermal catalytic water splitting involves nano-catalytic membrane. Two or more of these ways can be combined to produce hydrogen.

The Sabatier reaction, can be performed chemically or biologically in so called methanogenesis reaction.

Biological reactions have mild conditions of temperature and pressure (so for these reasons are more advantageous) but these processes are complex and with insufficient knowledge.

The catalytic methanation process is well understood and is used for many years in various industrial applications, as in ammonia production by removing trace amounts of $\mathrm{CO}_{2}$. The process typically occurs at around $573 \mathrm{~K}$, and at pressures of 50-200 bar. However, in the catalytic methanation the impurities, such as hydrogen sulphide and siloxanes, have to be removed prior to the catalytic step, against to biological methanation. Experimental investigations show that $\mathrm{CO}_{2}$ and $\mathrm{H}_{2}$ can be converted with selectivity close to $100 \%$, while the overall energy conversion efficiency is equal to $80 \%$ [8]. In general catalysts as nickel-based, on an alumina carrier are used to reduce the activation energy allowing to proceed at more fast rates [9]. 
Biological methanation is carried out by some microorganisms as hydrogenotrophic methanogens, that consume hydrogen and carbon dioxide to produce methane.

These are strictly anaerobic microbes of the archaea domain that generally grow at 323-343 K and only with hyperthermophiles it is possible to work at $383 \mathrm{~K}$.

The free energy associated with the biological reaction is equal to $-131 \mathrm{~kJ} / \mathrm{mol}$ [10], suggesting that the process is favorable. Gases in this reaction do not have to be from a highly purity grade.

The selectivity has good results; the microorganisms metabolize the $95 \%$ of gaseous substrate to $\mathrm{CH}_{4}$ and only $5 \%$ to biomass.

The efficiency of biological methanation is around equal to $80 \%$ due to the exothermic reaction [8].

This process can be carried out in different way: "in-situ" by injecting hydrogen into an anaerobic digester $[11,12]$ "exsitu" in a separate vessel $[8,13,14]$.

The biological Sabatier reaction follows a complex reaction network according five degradation steps: (a) disintegration of complex substrates to macromolecules, (b) hydrolysis of these to smaller molecules, (c) acidogenesis, (d) acetogenesis, where acids are produced, (e) methanogenesis where methane is produced within two different pathways.

Some microbial species produce hydrogen as a byproduct of the acetogenesis [15] and acetic acid is degraded to methane and carbon dioxide; carbon dioxide is consumed by hydrogenotrophic microorganisms producing methane.

This phase is only thermodynamically feasible, when the concentration of hydrogen is low, because it is a product of the reaction.

For these reason important is the mass transfer from the gas to the liquid phase, used also to describe other systems involving absorption, chemical reactions and fermentations [16].

Themass transfer between the gas-liquid phases is influenced by some parameters as the energy dissipated by turbulence $(\varepsilon)$, the gas hold-up $(\varnothing)$, the size of the bubbles $\left(d_{b}\right)$, or their distribution within the volume being mixed. Those variables are a function of operational conditions (power input or stirrer speed and gas flow), physical properties of the solution and gas phase (viscosity, surface tension and density), the geometry of the vessel, the stirrer and the gas distributor [16].

The mass transfer rate is proportionalthrough the volumetric mass transfer coefficient $\mathrm{k}_{\mathrm{La}}$ to the concentration gradient(see Eq. 2):

$\frac{d C}{d t}=k_{L} a \cdot\left(C^{*}-C\right)$ where $\mathrm{C}^{*}$ is the saturation concentration and $\mathrm{C}$ the concentration in liquid phase. This coefficient of proportionality is used to develop the design and scale-up of contactors, chemical reactors and bioreactors, though it is not sufficient to understand the mass transfer mechanisms. For this reason, the separation of the parameters $\mathrm{k}_{\mathrm{L}}$ and aare considered for a better comprehension of the gas-liquid mass transfer mechanisms.

$\mathrm{K}_{\mathrm{L}}$ is the mass transfer coefficient influenced bythe flow properties of the liquid and the diffusivity of the gas; it can be estimated by empirical and theorical model divided in different approaches. Some of them are based on the concept of a rigid interface, others on an interface where surface renewal occurs through the displacement of liquid at the interface or a combination of both concepts [16].

$\mathrm{a}$ is the gas-liquid specific interfacial area and is a characteristic for different flow regime: is influenced by turbulence, viscosity of liquid and the diffuser used to distribute the gas. In literature there are several correlations to determinate the specific interfacial area although their application is very limited [16].

Also different equations are present in literature to calculate the volumetric mass transfer in single and multiple-impeller systems with different volumes, and for Newtonian and nonNewtonian liquids.

Usually, $\mathrm{k}_{\mathrm{La}}$ values are provided by following equation (see Eq. 3):

$k_{L} a=C \cdot V_{s}^{a} \cdot(P / V)^{b} \cdot \mu^{c}$

the exponent values $(\mathrm{a} b$ and $\mathrm{c}$ ) vary with the proposed correlations [16]according the differences in geometric configurations (vessel and stirrer diameters, stirrer and distributor of gas types) and in the properties of liquid (density, surface tension and viscosity) [17]. This equation suggeststhat, under mass transfer-limiting conditions, with the increase of the impeller rate some factors asP/V, $\mathrm{K}_{\mathrm{L} a}$, and hence the reactor productivity increase.

However, the results from different equations do not agree with others $[18,17,19,20]$.

These equations can be theoretical $[21,22,23,24]$ or predictive $[25,16,26,27,28]$. However, the application of theoretical equations is limited: it is very difficult to develop a fluid-dynamic model that can predict different parameters as $\mathrm{d}_{\mathrm{b}}, \emptyset, \mathrm{a}, \mathrm{k}_{\mathrm{L}}$ under several operational conditions and volumes. In literature there are few works about the study of volumetric mass transfer coefficient $\mathrm{k}_{\mathrm{La}}$ with computational fluid dynamics (CFD) [29] as for bubble column and with chemical reaction, in particular the Fisher-Tropsch synthesis $[30,31]$.

The two film theory can be used to evaluate the mass transfer from gas to liquid [32], describing the flux through 
each film as the product between the driving force and the mass transfer coefficient (see Eq. 4):

$J=K_{L} \cdot\left(C^{*}-C_{L}\right)$

where $\mathrm{J}$ is the molar flux of oxygen $\left(\mathrm{mol} \cdot \mathrm{m}^{-2} \mathrm{~s}^{-1}\right)$ through the gas-liquid interface, $\mathrm{C}_{\mathrm{L}}$ is the dissolved oxygen concentration in the bulk liquid, $\mathrm{C}^{*}$ is the saturation concentration in the bulk liquid in equilibrium to the bulk gas phase, according to Henry's law $\left(\mathrm{p}^{*}=\mathrm{H} \cdot \mathrm{C}^{*}\right), \mathrm{K}_{\mathrm{L}}$ is the overall mass transfer coefficients. In general, the greatest resistance for mass transfer is on the liquid side of the interface and for this reason the gas phase resistance can be neglected: the overall mass transport coefficient is equal to the local coefficient and then $\mathrm{K}_{\mathrm{L}}=\mathrm{k}_{\mathrm{L}}$.

The mass transfer rate per unit of reactor volume, $\mathrm{N}$, is obtained multiplying the overall flux $\mathrm{J}$ and the gas-liquid interfacial area per unit of liquid volume, a (see Eq. 5):

$N=a \cdot J=k_{L} a \cdot\left(C^{*}-C_{L}\right)$

This research aims to study the fluid dynamic and the mass transfer rate per unit of reactor volume for biological Sabatier reaction inside the anaerobic digester through computational fluid dynamics analysis, improving the work of Leonzio [33]. COMSOL Multiphysics ${ }^{\mathrm{TM}} 4.2$ is used as software being a valuable tool to study the hydrodynamic performance of anaerobic digester. In literature there are not present works about the simulation of biological Sabatier reaction with CFD analysis.

Experimental values of methane evolution rate and equilibrium constant [34] are used considering Methanothermobacter marburgensis grown in chemostat conditions. The anaerobic digester is set as CSTR with constant volume while the Sabatier reaction is in equilibrium condition. The system mixing consists of three manifolds distributed on different floors and external sludge re-circulating pumps. A sensitivity analysis is carried out to evaluate the influence of reactor pressure on methane evolution rate and methane content in the off gas: the effect is positive for the two responses.

\section{MATERIALS AND METHODS}

\subsection{CFD Mathematical Model}

Computational fluid dynamics is a valuable and efficient tool used to understand and evaluate the fluid dynamics of flow systems. COMSOL Multiphysics ${ }^{\mathrm{TM}} 4.2$ software is used for simulations in order to study the system mixing carried out by external re-circulating pumps and then the volumetric mass transfer coefficient. In the mathematical model, the following assumptions are considered: the digestion occurs at constant temperature equal to $308 \mathrm{~K}$; the manure slurry has a non-Newtonian pseudo-plastic fluid behavior when TS $\geq 2.5 \%$; density is equal to 1001.73 $\mathrm{kg} / \mathrm{m}^{3}$ and viscosity is 2 Pas [34]; phase gas is constituted by hydrogen; the BMP of the liquid manure is equal to $5162 \mathrm{~kg}^{-}$

${ }^{1}$ VS. During the anaerobic digestion, gas species diffuse from the interface of the bubbles into the slurry whit a rate according the bubble size. In the slurry, chemical species diffuse towards the hydrogenotrophic methanogens and react to produce hydrocarbons. The slurry is assumed to be perfectly mixed: the liquid phase is treated as a continuous phase while the gas phase is treated as a dispersed phase. Each simulation is carried out under steady-state conditions and at each time step the iterative calculation converges when all the residuals have a value below $1 \cdot 10^{-5}$; a final convergence is obtained when the average velocity of the liquid phase achieves a constant value.

\subsubsection{Governing Equations}

The mathematical model used to describe the analyzed system is the standard k- $\varepsilon$ [36] mixture turbulence model accounting the effect of turbulence and solved for the average velocity; the Eulerian-Eulerian approach (two phase) is developed for the hydrodynamics of multiphase in the bubble reactor [37, 38, 39]. Equations about the conservation of continuity and momentum are solved for each phase and are the following (see Eq. 6 and 8):

Continuity equation

$\frac{\partial}{\partial t}\left(\rho_{k} \cdot \varepsilon_{k}\right)+\nabla\left(\rho_{k} \cdot \varepsilon_{k} \cdot u_{k}\right)=0$

where $\rho_{\mathrm{k}}$ is the density, $\varepsilon_{\mathrm{k}}$ is the volume fraction and $\mathrm{u}_{\mathrm{k}}$ is the velocity of phase $\mathrm{k}=\mathrm{L}$, for which is (see Eq. 7):

$\sum_{k} u_{k}=1$

Momentum equations

$$
\begin{aligned}
\frac{\partial}{\partial t}\left(\rho_{k} \cdot \varepsilon_{k} \cdot u_{k}\right)+ & \nabla\left(\rho_{k} \cdot \varepsilon_{k} \cdot u_{k} \cdot u_{k}\right) \\
& =-\varepsilon_{k} \cdot \nabla P+\nabla \tau_{k}+\rho_{k} \cdot \varepsilon_{k} \cdot g \\
& +F_{i, k}
\end{aligned}
$$

where $\mathrm{P}$ is the pressure shared by two phases, $\mathrm{Fi}_{{ }_{\mathrm{K}}}$ represents the interface momentum exchange, the term $\tau_{\mathrm{K}}$ is the stressstrain tensors, $g$ the gravity acceleration $\left(\mathrm{m} / \mathrm{s}^{2}\right)$. The share of flow domain for each phase (that has its velocity and physical properties) is provided by its volume fraction. Interactions between phases due to differences in velocity are expressed in the inter-phase transfer terms of the transport equations. The inter-phase forces considered for this simulation are the drag force between liquid and gas (represented by Khopkar et al.[40]) and the turbulent dispersion force. The turbulence model for bubbly flows is similar to the single-phase k- $\varepsilon$ turbulence model, however, there are other terms to consider the extra production of turbulence determined by the relative flow between gas bubbles and liquid. A turbulent viscosity is added to physical viscosity in the momentum transport equation and is modeled as (see Eq. 9):

$\eta_{T}=\rho \cdot C \cdot \mu \cdot k / \varepsilon$ 
where $C \cdot \mu$ is a model constant, $\rho$ is the density $\left(\mathrm{kg} / \mathrm{m}^{3}\right)$, eis the turbulent dissipation rate $\left(\mathrm{m}^{2} / \mathrm{s}^{3}\right)$, $\mathrm{k}$ the turbulent kinetic energy $\left(\mathrm{m}^{2} / \mathrm{s}^{3}\right)$. The transport equation for the turbulent kinetic energy $\mathrm{k}$ is provided (see Eq. 10):

$$
\begin{aligned}
\rho_{l} \cdot \frac{\partial k}{\partial t}- & \nabla\left[\left(\eta+\eta_{T} / \sigma_{k}\right) \cdot \nabla k\right]+\rho_{l} \cdot u_{l} \cdot \nabla k \\
& =1 / 2 \cdot \eta_{T} \cdot\left(\nabla u_{l}+\left(\nabla u_{l}\right)^{T}\right)^{2}-\rho_{l} \cdot \varepsilon \\
& +S_{k}
\end{aligned}
$$

where $\eta_{\mathrm{T}}$ is the turbulent viscosity $\left(\mathrm{m}^{2} / \mathrm{s}\right), \eta$ the liquid viscosity $\left(\mathrm{m}^{2} / \mathrm{s}\right), \rho_{\mathrm{l}}$ the liquid density $\left(\mathrm{kg} / \mathrm{m}^{3}\right)$, $\mathrm{u}_{1}$ the liquid velocity $(\mathrm{m} / \mathrm{s}), \varepsilon$ the turbulent dissipation rate $\left(\mathrm{m}^{2} / \mathrm{s}^{3}\right), \sigma_{\mathrm{k}}$ is the TKE Prandtl number and $S_{k}$ as defined below. The equation for the turbulent energy dissipation rate $\varepsilon$ isgiven by (see Eq. 11):

$$
\begin{aligned}
\rho_{l} \cdot \frac{\partial \varepsilon}{\partial t}-\nabla[(\eta+ & \left.\left.\eta_{T} / \sigma_{k}\right) \cdot \nabla \varepsilon\right]+\rho_{l} \cdot u_{l} \cdot \nabla \varepsilon \\
& =1 / 2 \cdot C_{\varepsilon 1} \cdot \varepsilon /_{k} \cdot\left(\nabla u_{l}+\left(\nabla u_{l}\right)^{T}\right)^{2} \\
& -\rho_{l} \cdot C_{\varepsilon 2}+S_{k}
\end{aligned}
$$

where $\eta_{T}$ is the turbulent viscosity $\left(\mathrm{m}^{2} / \mathrm{s}\right), \eta$ the liquid viscosity $\left(\mathrm{m}^{2} / \mathrm{s}\right), \rho_{1}$ the liquid density $\left(\mathrm{kg} / \mathrm{m}^{3}\right)$, $\mathrm{u}_{1}$ the liquid velocity $(\mathrm{m} / \mathrm{s}), \varepsilon$ the turbulent dissipation rate $\left(\mathrm{m}^{2} / \mathrm{s}^{3}\right), \sigma_{\mathrm{k}}$ is the TKE Prandtl number and $\mathrm{S}_{\mathrm{k}}$ as defined below, $\mathrm{C}_{2 \varepsilon}$ and $\mathrm{C}_{1 \varepsilon}$ the model constants, $\mathrm{k}$ is the turbulent kinetic energy $\left(\mathrm{m}^{2} / \mathrm{s}^{3}\right)$. The term $\mathrm{S}_{\mathrm{k}}$ considers the induced bubbles turbulence and is provided by this equation (see Eq. 12):

$S_{k}=-C_{k} \cdot \epsilon_{g} \cdot \nabla p \cdot u_{\text {slip }}$

where $\mathrm{u}_{\text {slip }}$ is the slip velocity $(\mathrm{m} / \mathrm{s}), \epsilon_{g}$ the gas holdup, $\mathrm{C}_{\mathrm{K}}$ a constant of model, $\mathrm{P}$ the reactor pressure. For the gas phase's velocity field, a drift velocity is considered (see Eq. $13)$ :

$u_{g}=u_{l}+u_{\text {slip }}+u_{\text {drift }}$

where drift velocity is equal as (see Eq. 14):

$$
u_{d r i f t}=\eta_{T} \cdot \nabla \epsilon_{g} / \rho_{l} \cdot \epsilon_{g}
$$

where $\eta_{\mathrm{T}}$ is the turbulent viscosity $\left(\mathrm{m}^{2} / \mathrm{s}\right), \epsilon_{g}$ the gas holdup, $\rho_{\mathrm{l}}$ is the liquid density $\left(\mathrm{kg} / \mathrm{m}^{3}\right)$.

The value of turbulence model parameters is present in the database of COMSOL. The dissolution of gas is calculated using two-film theory, calculating the mass transfer rate according to (see Eq. 15 and 16):

$$
\begin{aligned}
& m_{g l}=k \cdot\left(P_{\text {rif }}+P /{ }_{H}-c\right) \cdot a \\
& a=(4 \cdot n \cdot \pi)^{\frac{1}{3}} \cdot\left(3 \cdot e_{g}\right)^{\frac{2}{3}}
\end{aligned}
$$

where a is interfacial area, which depends on the volume fraction of gas and the number of bubbles per volume, $n$ $\left(1 / \mathrm{m}^{3}\right)$, $\mathrm{H}$ the Henry's constant $\left(\mathrm{Pam}^{3} / \mathrm{mol}\right)$, c the concentration of gas dissolved in liquid $\left(\mathrm{mol} / \mathrm{m}^{3}\right), \mathrm{k}$ the mass transfer coefficient $(\mathrm{m} / \mathrm{s}), \mathrm{e}_{\mathrm{g}}$ the gas holdup, $\mathrm{P}$ the pressure. In two-film theory model it is assumed that bubbles cannot split or merge. The following parameters are assumed for the two film theory: mass transfer coefficient of hydrogen inside the anaerobic digester is equal to $0.00017 \mathrm{~m} / \mathrm{s}$ while Henry's constant of hydrogen is equal to $129898 \mathrm{Pam}^{3} / \mathrm{mol}$. In the mathematical model of COMSOL some important constants are set of default as shown in table 1:

Table -1: Constants of simulated model

\begin{tabular}{|l|l|}
\hline Constants & Values \\
\hline $\mathrm{C} \mu$ & 0.09 \\
\hline $\mathrm{C}_{1 \varepsilon}$ & 1.44 \\
\hline $\mathrm{C}_{2 \varepsilon}$ & 1.92 \\
\hline TKE Prandtl Number $\left(\sigma_{\mathrm{k}}\right)$ & 1 \\
\hline TDE Prandtl Number $\left(\sigma_{\varepsilon}\right)$ & 1.3 \\
\hline Dispersion Prandtl Number & 0.75 \\
\hline Energy Prandtl Number & 0.85 \\
\hline Wall Prandtl Number & 0.85 \\
\hline Turbolent Schmidt Number & 0.7 \\
\hline
\end{tabular}

\subsubsection{Boundary Conditions and Initial Values}

For a given system, it is necessary to specify the appropriate initial and boundary conditions. The boundary conditions are specified for each anaerobic digester during the simulations. Boundary conditions are set considering that the maximum value of suction velocity of fluid is between $2-2.5 \mathrm{~m} / \mathrm{s}$, while the inlet velocity of fluid is between 0.5 and $1 \mathrm{~m} / \mathrm{s}$. No-slip boundary conditions are imposed on all wall surfaces. Normal inflow velocity equal to $2 \mathrm{~m} / \mathrm{s}$ and normal outflow velocity equal to $0.5 \mathrm{~m} / \mathrm{s}$ are set for suctions and feed manifolds respectively. In this way the inlet of fluid is axially to surface of anaerobic digester. The gas flux and the number density flux are set for the surface where the hydrogen is insufflated. In two-phase flow simulation, the reactor is filled with liquid while gas is feeded from the upperof the reactor.

\subsection{Modeling of Sabatier Reaction}

Reaction Engineering package is used to simulate the Sabatier reaction and the experimental value of Bernacchi et al. [34] are considered for the kinetic data considering that Methanothermobactermarburgens is grow in chemostat conditions. In chemical reaction, the solubility of carbon dioxide in water is higher than the solubility of hydrogen, so the hydrogen transfer rate is the limiting factor. The reactor is set as CSTR whit constant volume while the Sabatier reaction in equilibrium condition. Infect the mass and energy balance equations that describe these systems assume perfect or well defined mixing conditions. The value of density and molecular weight are inserted. For $\mathrm{CO}_{2}, \mathrm{H}_{2}$, $\mathrm{CH}_{4}, \mathrm{H}_{2} \mathrm{O}$ are set respectively this value for initial concentration: $12 \mathrm{~mol} / \mathrm{m}^{3}, 12 \mathrm{~mol} / \mathrm{m}^{3}, 2 \mathrm{~mol} / \mathrm{m}^{3}, 1 \mathrm{~mol} / \mathrm{m}^{3}$. 


\subsection{Geometry of Anaerobic Digester}

The anaerobic digester in figure 1 has a 3D cylindrical geometry (see table 1). The system mixing consist of three manifolds distributed on different floors and external sludge re-circulating pumps. Each manifold has four radial suction nozzles, aligned with one another. Their section is different to have the value of velocity constant to change in flow. The external re-circulating pumps are grinder in order to grind all the solid particles still not dissolved within the fluid. These are placed on the same floor of the digester improving the aspiration of the sludge. The feed is perpendicular to the top of digester with three nozzles, as shown in figure 1. Pumps are simulated as virtual areas across for which value of velocity is set.

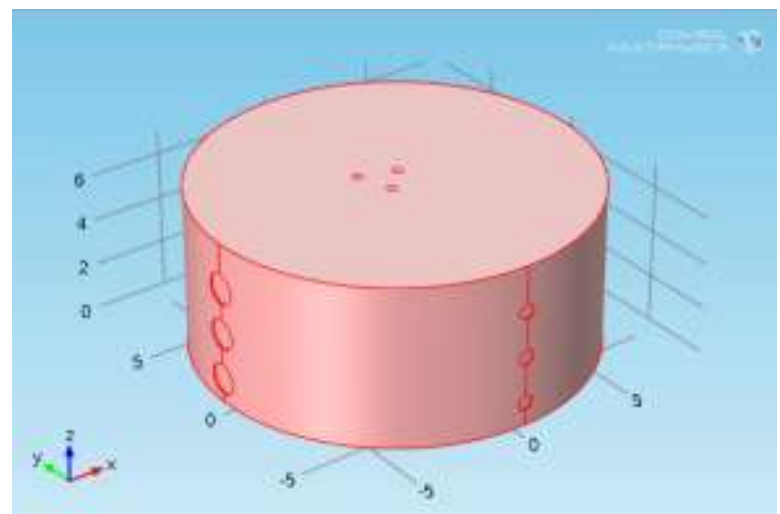

Fig. 1. Geometry of anaerobic digester in $3 \mathrm{D}$ carried out in COMSOL Multiphysics environmental

Table -2: Geometric values of anaerobic digester

\begin{tabular}{|lll|}
\hline Geometry of anaerobic digester & & \\
\hline Inside radius & 8 & $\mathrm{~m}$ \\
\hline Internal height & 7 & $\mathrm{~m}$ \\
\hline Radius of inlet nozzles & 0.2 & $\mathrm{~m}$ \\
\hline Area of inlet nozzles & 0.13 & $\mathrm{~m}^{2}$ \\
\hline Radius of $1^{\circ}$ suction nozzle & 0.66 & $\mathrm{~m}$ \\
\hline Radius of $2^{\circ}$ suction nozzle & 0.47 & $\mathrm{~m}$ \\
\hline Radius of $3^{\circ}$ suction nozzle & 0.38 & $\mathrm{~m}$ \\
\hline Radius of $4^{\circ}$ suction nozzle & 0.33 & $\mathrm{~m}$ \\
\hline Area of $1^{\circ}$ suction nozzle & 1.36 & $\mathrm{~m}^{2}$ \\
\hline Area of $2^{\circ}$ suction nozzle & 0.68 & $\mathrm{~m}^{2}$ \\
\hline Area of $3^{\circ}$ suction nozzle & 0.45 & $\mathrm{~m}^{2}$ \\
\hline Area of $4^{\circ}$ suction nozzle & 0.34 & $\mathrm{~m}^{2}$ \\
\hline Height of $1^{\circ}$ manifold from ground & 1 & $\mathrm{~m}$ \\
\hline Height of $2^{\circ}$ manifold from ground & 3 & $\mathrm{~m}$ \\
\hline Height of $3^{\circ}$ manifold from ground & 5 & $\mathrm{~m}$ \\
\hline
\end{tabular}

The flow domain of geometry is discretized into tetrahedral meshes elements of fine size according physic-controlled mesh. Then the finite volume method is used to discretize the governing equations. The terms in all equations and in particular the convection and diffusion terms are discretized by central differencing scheme.

\section{RESULTS AND DISCUSSIONS}

Once the system has been designed the efficiency of the mixture can be verified through velocity profiles that vary with time and location inside the reactor. In this contest CFD method is used as general numerical approach to study the mixing and flu dynamic inside the anaerobic digester.

However, after some time the profile velocity has not changes: the reactor has come to a quasi-steady state. Infect velocity is considered the more representative parameter of flow behavior. Figure 2 shows the velocity profile of liquid phase for a 3D anaerobic digestion. The value of velocity varies from $8.19 \cdot 10^{-4} \mathrm{~m} / \mathrm{s}$ to $1.82 \cdot 10^{-3} \mathrm{~m} / \mathrm{s}$ : the higher values of velocity are not inside the digester but near the mixing system. The obtained magnitude of velocity, in the three cases, is in agree with the work of López-Jiménez et al. [41] for an anaerobic digester.



Fig. 2. Profile of liquid phase velocity $(\mathrm{m} / \mathrm{s})$ inside the anaerobic digester

The efficiency of the mixing system and the homogeneity inside the reactor is shown by figure 3: the higher relative volume has the higher values of velocity. From simulations it is possible to find the average value, standard deviation and variance of velocity that are respectively equal to: $0.0014 \mathrm{~m} / \mathrm{s}, 0.00022 \mathrm{~m} / \mathrm{s}, 4,88 \cdot 10^{-8} \mathrm{~m} / \mathrm{s}$. Statistical methods are used by many researchers to evaluate the mixing/uniformity index in anaerobic digestion [42].

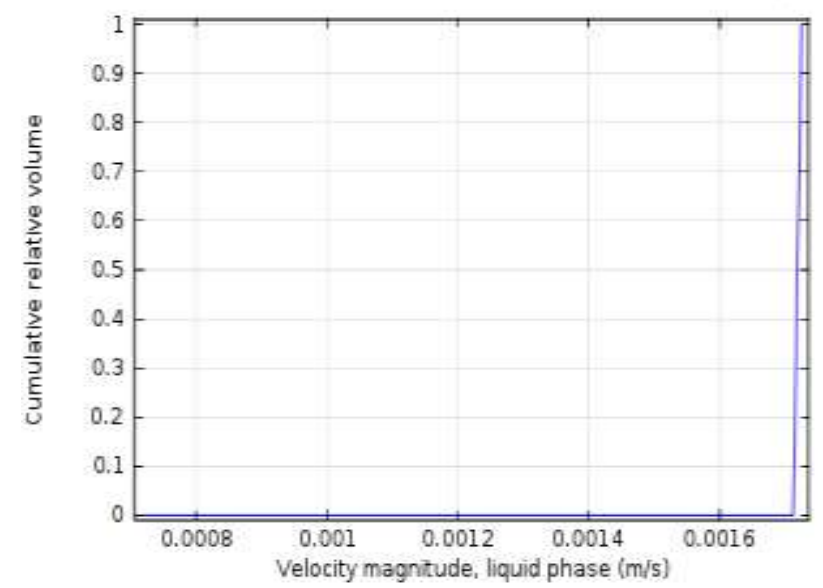

Fig. 3. Histogram of liquid phase velocity $(\mathrm{m} / \mathrm{s})$ inside the anaerobic digester 
For this system the standard deviation suggests that there is a good mixing system and the dead zones are lower, that are the zones of the anaerobic digester with no flow or very low velocities of liquid(less than $5 \%$ of the maximum velocity)[43]. Dead zones are undesirable, because there are regions with no mixing, reducing the efficiency of the reactor. Infect both $\mathrm{pH}$ and temperature increase, degrading the digester performance. Figure 4 shows the turbulent dissipation rate inside the anaerobic digester: for the higher velocity there are the higher values of turbulent dissipation rate.

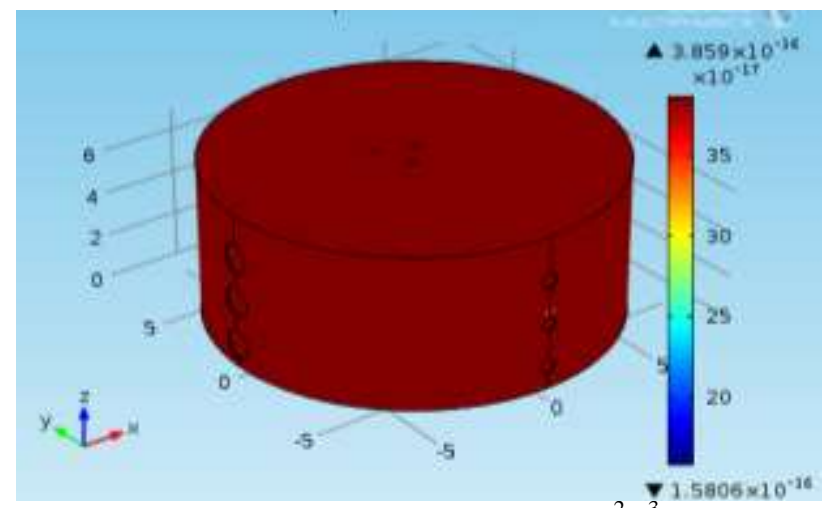

Fig. 4. Turbulent dissipation rate profile $\left(\mathrm{m}^{2} / \mathrm{s}^{3}\right)$ inside the anaerobic digester

Figure 5 shows the profile of mass transfer from gas to liquid inside the anaerobic digester in $\mathrm{kg} / \mathrm{m}^{3} \mathrm{~s}$. The maximum value of mass transfer gas to liquid is 0.09 $\mathrm{kg} / \mathrm{m}^{3} \mathrm{~s}$ : high values are required for stirred tank reactor. A common method used to enhance the gas-to-liquid mass transfer in stirred tanks is to increase the agitator's powerto-volume ratio that increases the bubble breakup; this phenomenon increases thethe interfacial area available for mass transfer, but it is not economically feasible, due to higher power costs.

Consequently, alternative geometric configurations that may provide more energy-efficient mass transfer must be developed for the anaerobic digester. Literature shows that it is recommended to have the gas transfer of $\mathrm{H}_{2}$ to the liquid phase as high as possible to not reduce the volumetric MER (Methane Evolution Rate) and negatively impact on $\mathrm{CH}_{4}$ off gas quality.

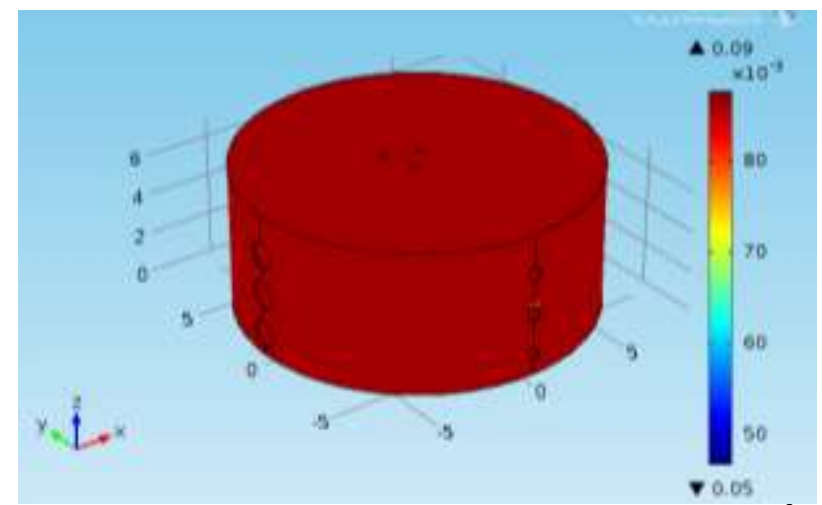

Fig. 5. Profile of mass transfer from gas to liquid $\left(\mathrm{kg} / \mathrm{m}^{3} \mathrm{~s}\right)$ for anaerobic digester
The gas holdup, a relevant hydrodynamic parameter for multi-phase system, plays an important role in gas-liquid mass transfer: higher the gas holds up higher is the mass transfer rate of the gas. This suggest that the gas holds up decreases with the increase in liquid velocity due to the dissolution of gas into liquid [29]. Infect confronting the figure 2 and 5 with higher velocity of liquid there are the higher mass to transfer from gas to liquid.

The gas liquid mass transfer is influenced by some parameters as reactor geometry, number, positioning and type of used stirrers, agitation, gas concentration, reactor pressure. Among of them, the gassing rate, the reactor pressure and the stirrer speed are easily controlled. For these reason a sensitivity analysis varying the pressure inside the reactor is carried out for the analyzed system. The reactor pressure influences the equilibrium concentrations of the gasses in the liquid phase and then the driving forces.

The volumetric methane production rate and the $\mathrm{CH}_{4}$ concentration in the product gas are considered as responses because they are the most important parametersin the industry. The MER influences the size of the anaerobic digester and therefore the investment and energy costs. For this reasons it is necessary to optimize the volumetric production rate of the process in order to have lower investment and energy costs. The pressure has a positive effect on MER and methane concentration: when the reactor pressure is increased at a given inflow rate however, the MER and the $\mathrm{CH}_{4}$ content in the off gas rise, as shown in figure 6 and 7. Infect the higher pressure has a positive effect on the partial pressure of the reactants in the gas phase and therefore on the equilibrium concentrations of liquid phase.

These results are in agreement with the experimental data reported in the work of Seifert et al. [44] where an increase of pressure will have a high influence on methane concentration of gas but a little effect on MER, as discussed by Seifert et al. [45].

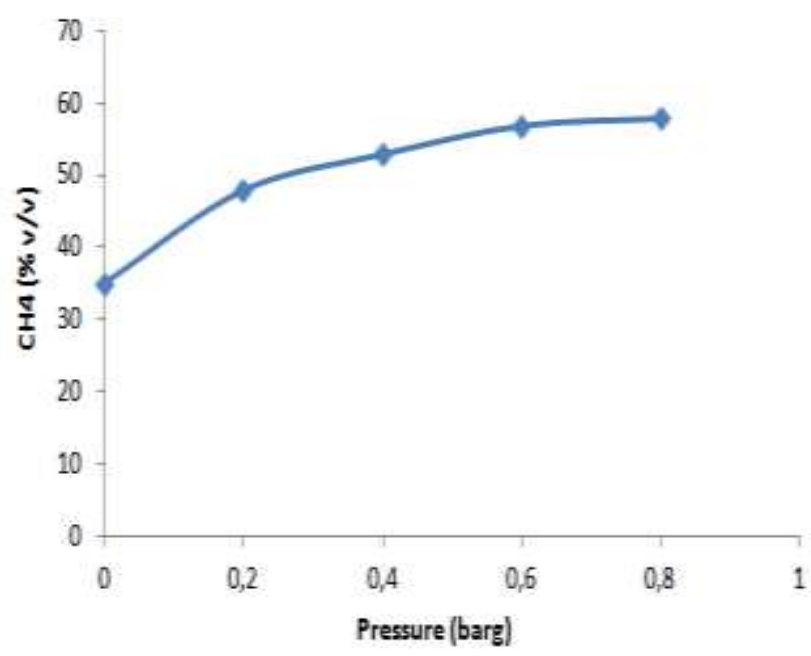

Fig. 6. Influence of pressure on $\mathrm{CH}_{4}$ off gas content for anaerobic digester 


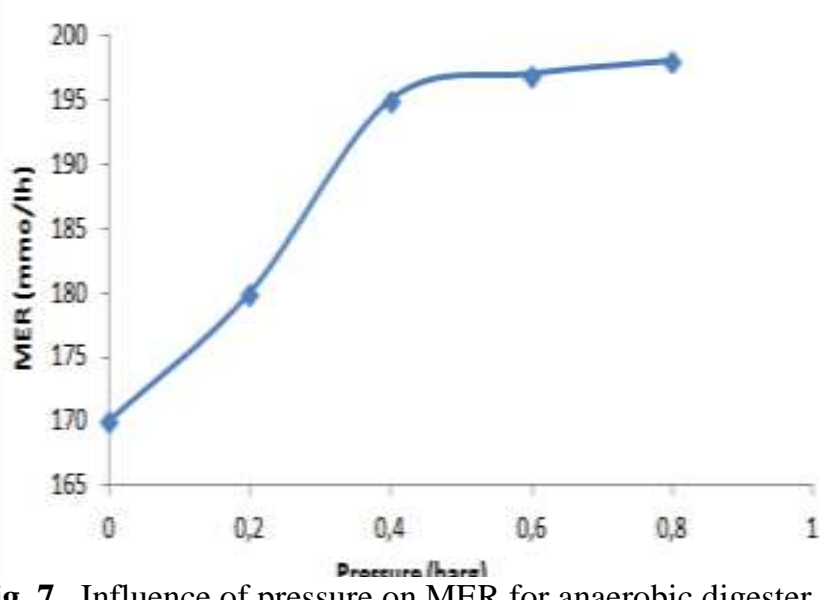

Fig. 7. Influence of pressure on MER for anaerobic digester

Figure 7 shows that MER achieves a maximum value immediately after the pressure rise, due to the increased gas liquid mass transfer. For this reason, an increase of the gassing rate will determine a higher $\mathrm{MER}_{\max }$.

Infect the gassing rate influences directly to the $\mathrm{k}_{\mathrm{La}}$ value as long as the flooding point of the stirrer is not exceeded. Furthermore, it establishes the value of theoretical maximum MER in function of the carbon dioxide and hydrogen inflow rates.

The increase of gassing rate lowers the methane concentration because the mass transfer of hydrogen is already limiting at the lowest gassing rate values and an increase of methane concentration of gas can be achieved by the increase of gas inlet rate [46]. Infect the gas bubble surface does not increase in the same proportion as the gas inflow is raised and because the residence time of the gas in the liquid decreases.

\section{CONCLUSIONS}

The biological conversion of hydrogen and carbon dioxide into methane, using methanogenic archaea is an interesting technology for carbon dioxide conversion, energy storage and biogas upgrading. The optimization and the study of this reaction in industrial area is an important issue.A study about fluid dynamics simulation using CFD analysis is carried out with COMSOL Multiphysics ${ }^{\mathrm{TM}} 4.2$ to evaluate the mixing inside the anaerobic digester where take place the biological Sabatier reaction. The system mixing consist of three collectors distributed on different floors and external sludge re-circulating pumps. Each collector has four radial suction manifold, aligned with one another. Velocity profile suggest that the mixing system ensure a good mixing. The maximum and minimum value of velocity inside the anaerobic digester are respectively equal to $8.19 \cdot 10^{-4} \mathrm{~m} / \mathrm{s}$ to $1.82 \cdot 10^{-3} \mathrm{~m} / \mathrm{s}$.

For biological Sabatier reaction a sensitivity analysis varying the reactor pressure is carried out. The volumetric methane production rate and the $\mathrm{CH}_{4}$ concentration in the product gas are considered as responses. The reactor pressure has a positive effect on MER and the $\mathrm{CH}_{4}$ content in the off gas. The plot shows that MER achieves a maximum value after the pressure rise due to the increased gas liquid mass transfer.

Another important parameter is the gassing rates: it has a positive effect on $\mathrm{kLa}$ and then on the MER. However, the conversion efficiency decreases at higher gassing rates, that can however be compensated by a simultaneous increase of the reactor pressure. Both parameters can be combined to obtain high volumetric productivity at high off gas quality.The design of bioreactors, now restrict more increase in gas flow rate and reactor pressure. This suggests, that the interdisciplinary bridges from bio-processing to chemical reactor design must be followed in the future to boot this promising bioprocess to gain bio-methane via $\mathrm{CO}_{2}$ fixation.

\section{ACKNOWLEDGEMENT}

The author of the study would like to thank the European Commission for funding this work.

\section{REFERENCES}

[1]. A. Soman, Y. Shastri, Optimization of novel photobioreactor design using computational fluid dynamics. Applied Energy. 140 (2015) 246-255.

[2]. J. Browne, A.S. Nizami, T. Thamsiriroj, J.D. Murphy, Assessing the cost of biofuel production with increasing penetration of the transport fuel market: a case study of gaseous biomethane in Ireland. Renew Sustain Energy Rev Dec. 15 (9) (2011) 4537-47.

[3]. W. Urban, K. Girod, H. Lohmann, Technologien und Kosten der Biogasaufbereitung und Einspeisung in das Erdgasnetz. Ergebnisse der Markterhebung 2007e2008 2009 [Online]. Available from: http://publica. fraunhofer.de/dokumente/N-94887.html [accessed 30.07.14].

[4]. T. Probert, Pipe dreams? Carbon capture ready and retrofitting gas-fired power plants. Gas Turbine World 2011 [Online]. Available from: http://millicentmedia.com/2012/03/21/pipe-dreams-carboncapture-ready-andretrofitting-gas-fired-power-plants/ [accessed 08.07.14].

[5]. K.Z. House, A.C. Baclig, M. Ranjan, E.A. van Nierop, Wilcox J, Herzog HJ. Economic and energetic analysis of capturing $\mathrm{CO}_{2}$ from ambient air. Proc Natl Acad Sci U S A Dec. 108 (51) (2011) 20428-33.

[6]. V. Barbarossa, G. Vanga, Alternative use of $\mathrm{CO}_{2}, \mathrm{EAI}$, Energia Ambiente Innovazione, 2011.

[7]. J. Ralston, The Sabatier Reaction, Possible Solution to $\mathrm{CO}_{2}$ Emissions, http://www.pennenergy.com/articles/pennenergy/2010/03/th e-sabatier-reaction.html

[8]. G. Benjaminsson, J. Benjaminsson, R. Boogh Rudberg, Power-to-Gas A technical review, SGC Rapport 2013: 284 Available at http://www.sgc.se/en/?pg=1445651.

[9]. E.P. Ahern, P. Deane, T. Persson, B.O. Gallachoir, J.D. Murphy, A perspective on the potential role of renewable gas in a smart energy island system, Renewable Energy. 78 (2015) 648-656. 
[10]. M. Madigan, Brock biology of microorganisms. 13th ed. International Microbiology. 2012, 334.

[11]. T. Persson, D. Baxter, Task 37 Country Reports Summary 2014, IEA Bioenergy Task 37, Available at http:/www.iea-biogas.net/country-reports.html.

[12]. M. Burkhardt, T. Koschack, G. Busch, Biocatalytic methanation of hydrogen and carbon dioxide in an anaerobic threephase system, Bioresource Technology. 178 (2015) 330-333.

[13]. G. Luo, I. Angelidaki, Co-digestion of manure and whey for in situ biogas upgrading by the addition of $\mathrm{H} 2$ : process performance and microbial insights. Appl Microbiol Biotechnol. 97 (3) (2013) 1373-81.

[14]. G. Leonzio, Process analysis of biological Sabatier reaction for bio-methane production. Chemical Engineering Journal. 290 (2016) 490-498.

[15]. B. Demirel, P. Scherer, The roles of acetotrophic and hydrogenotrophic methanogens during anaerobic conversion of biomass to methane: a review. Rev Environ Sci Biotechnol. 7 (2) (2008) 173-90.

[16]. F. Garcia-Ochoa, E. Gomez, Theoretical prediction of gas-liquid mass transfer coefficient, specific area and holdupin sparged stirred tanks, Chemical Engineering Science. 59 (2004) 2489 - 2501.

[17]. P.R. Gogate, A.A.C.M. Beenackers, A.B. Pandit, Multiple-impeller systems with a special emphasis on bioreactors: a critical review. Biochemical Engineering Journal. 6 (2000) 109-144.

[18]. F. Garcia-Ochoa, E. Gomez, Mass transfer coe\%cient in stirrer tank reactors for xanthan solutions. Biochemical Engineering Journal. 1 (1998) 1-10.

[19]. V. Linek, M. Kordac, T. Moucha, Mechanism of mass transfer from bubbles in dispersions Part II: Mass transfer coefficients in stirred gas-liquid reactor and bubble column, Chemical Engineering and Processing. 44 (2005) 121-130.

[20]. M. Bouaifi, G. Hebrard, D. Bastoul, M. Roustan, A comparative study of gas hold-up, bubble size, interfacial area and mass transfer coefficients in stirred gas-liquid reactors and bubble columns, Chemical Engineering and Processing. 40 (2001) 97-111.

[21]. Y. Kawase, B. Halard, M. Moo-Young, Theoretical prediction of volumetric mass transfer coefficients in bubble columns for Newtonian and non-Newtonian fluids. Chemical Engineering Science. 42 (1987) 1609-1617.

[22]. Y. Kawase, M. Moo-Young, Volumetric mass transfer coefficients in aerated stirred tank reactors with Newtonian and non-Newtonian media. Chemical Engineering Research Development. 66 (1988) 284-288.

[23]. E. Garcia-Calvo, A fluid dynamic model for airlift reactors. Chemical Engineering Sciences. 44 (1989) 321323 .

[24]. E. Garcia-Calvo, Fluid dynamic of airlift reactors: twophase friction factors. A.I.Ch.E. Journal. 38 (1992) 16621666.

[25]. M. Tobajas, E. Garcia-Calvo, M.H. Siegel, S.E. Apitz, Hydrodynamics and mass transfer prediction in a threephase airlift reactor for marine sediment biotreatment. Chemical Engineering Science. 54 (1999) 5347-5354.

[26]. J.M.T. Vasconcelos, S.C.P. Orvalho, A.M. Rodr Tguez, S.S. Alves, Effect of blade shape on the performance of six blade disk turbine impellers. Industrial Engineering Chem. Research. 39 (2000)203-208.

[27]. A.G. Pedersen, H. Andersen, J. Nielsen, J. Villadsen, A novel technique based on $\mathrm{Kr}-85$ for quanti'cation of gasliquid mass transfer in bioreactors. Chemical Engineering Science. 6 (49) (1994) 803-810.

[28]. V. Linek, J. Sinkule, P. Benes, Critical assessment of gassing-in method measuring $\mathrm{kLa}$ in fermentors. Biotechnology and Bioengineering. 38 (1991) 323-330.

[29]. A. Ali, K. M. CFD Simulation of Bubbly Flow Through a Bubble Column, International Journal of Scientific \& Engineering Research. 5 (2014) 4.

[30]. J.W.A. Swart, R. Krishna, Simulation of the transient and steady state behaviour of a bubble column slurry reactor for Fischer-Tropsch synthesis. Chemical Engineering and Processing. 41 (2002) 35-47.

[31]. A.A. Troshko, F. Zdravistchb, CFD modeling of slurry bubble column reactors for Fisher-Tropsch synthesis, Chemical Engineering Science. 64 (2009) 892-903.

[32]. F. Garcia-Ochoa, E. Gomez, Bioreactor scale-up and oxygen transfer rate in microbial processes: An overview, Biotechnology Advances. 27 (2009) 153-176.

[33]. G. Leonzio, Biological Sabatier reaction with CFD Analysis, The International Conference of Computational Methods in Sciences and Engineering 2016, 17-20 March, Athens Greece, AIP Conference Proceeding.

[34]. D.S. Bernacchi, A. Seifert, S. Rittmann, A. Krajete, Benefits of biological methanation. 2013 [Online]. Available from: http://www.dbigti.de/fileadmin/downloads/5_Veroeffentlichungen/Tagunge n_Workshops/2013/H2

Fachforum/14_Krajete_KrajeteGmbH.pdf 20.06.14].

[35]. B. Wu, S. Chen, CFD simulation of non-Newtonian fluid flow in anaerobic digesters. Biotechnol. Bioeng. 99 (3) (2008) 700-711.

[36]. V. Yakhot, S.A. Orszag, Renormalization group analysis of turbulence I: Basic Theory. Journal of Scientific Computing, 5 (1) (1986) 1-51.

[37]. P. Chen, J. Sanyal, M.P. Dudukovic, Numerical simulation of bubble columns flows: effect of different breakup and coalescence closures. Chemical Engineering Science. 60 (2005a) 1085-1101.

[38]. P. Chen, M.P. Dudukovic, J. Sanyal, Threedimensional simulation of bubble column flows with bubble coalescence and breakup. Fluid Mechanics and Transport Phenomena, 51 (3) (2005b) 696-712.

[39]. R. Krishna, M.I. Urseanu, J.M. van Baten, Ellenberger, J.; Influence of scale on the hydrodynamics of bubble columns operating in the churn-turbulent regime: experiments vs Eulerian simulation. Powder Technology. (1999) 100.

[40]. A.R. Khophkar, A.R. Rammohan, V.V. Ranade, M.P. Dudukovic, Gas-Liquid Flow Generated by a Rushton Turbine in Stirred Tank Vessel: CAPRT/CT Measurements and CFD Simulations, Chemical Engineering Science. 60 (2005) 2215.

[41]. P.A. López-Jiménez, J. Escudero-González, T.M. Martinez, V.F. Montana, C. Gualtieri, Application of CFD methods to an anaerobic digester: the case of Ontinyent 
WWPT, Valencia, Spain. Journal of water process engineering. 7 (2015) 131-140.

[42]. M. Terashima, R. Goel, K. Komatsu, et al. CFD simulation of mixing in anaerobic digesters. Bioresource Technology. 100 (2009) 2228-2233.

[43]. M.S. Vesvikar, M. Al-Dahhan, Flow pattern visualization in a mimic anaerobic digester using CFD. Biotechnol. Bioeng. 89 (6) (2005) 719-732.

[44]. A.H. Seifert, S. Rittmann, C. Herwig, Analysis of process related factors to increase volumetric productivity and quality of biomethane with Methanothermobacter marburgensis Appl Energ. 132 (2014) 155-162.

[45]. A. Seifert, S. Rittmann, S. Bernacchi, C. Herwig, Method for assessing the impact of emission gasses on physiology and productivity in biological methanogenesis. Bioresource Technol 136 (2013) 747-51.

[46]. A.K. Haydock, I. Porat, W.B. Whitman, et al. Continuous culture of Methanococcus maripaludis under defined nutrient conditions. FEMS Microbiol Lett. 238 (2004) 85-91.

\section{BIOGRAPHIES}

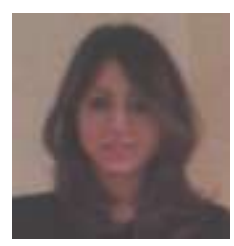

Grazia Leonzio is a $\mathrm{PhD}$ student at Department of Industrial and Information Engineering and Economics, University of L'Aquila, Via Giovanni Gronchi 18, 67100 L'Aquila, Italy;

e-mail: grazia.leonzio@graduate.univaq.it; 